Article

\title{
Effect of Nano-Materials on Autogenous Shrinkage Properties of Cement Based Materials
}

\author{
Xiaoyan Liu ${ }^{1}$, Tingchen Fang ${ }^{2, *}$ and Junqing Zuo ${ }^{2,3, *}$ \\ 1 College of Mechanics and Materials, Hohai University, Nanjing 210098, China \\ 2 Engineering General Institute, Shanghai Construction Group Co., Ltd., Shanghai 200080, China \\ 3 Shanghai Engineering Research Center of Mega Structure High Performance Concrete, \\ Shanghai 201114, China \\ * Correspondence: fangtc@scgtc.com.cn (T.F.); junqingzuo@163.com (J.Z.)
}

Received: 29 July 2019; Accepted: 3 September 2019; Published: 9 September 2019

check for updates

\begin{abstract}
This paper presents an experimental investigation on the effect of nano-montmorillonite, carbon nanotubes, and nano calcium carbonate on autogenous shrinkage of cement based materials. Cement paste with different nano-montmorillonite dosage (1.0 wt.\%, $2.0 \mathrm{wt} . \%, 3.0 \mathrm{wt} . \%)$, carbon nanotubes dosage $(0.1 \mathrm{wt} . \%, 0.2 \mathrm{wt} . \%, 0.3 \mathrm{wt} . \%)$, and nano calcium carbonate dosage (1.0 wt. $\%$, $2.0 \mathrm{wt} . \%, 3.0 \mathrm{wt} . \%$ ) were compared with the reference group to assess the effects of nano-materials on cement paste. Results show that autogenous shrinkage of cement based materials containing nano-materials mainly occurs in the first $72 \mathrm{~h}$. Nano-materials decrease the autogenous shrinkage of the investigated cement based materials at all ages. Compared with that of the reference group at the age of $168 \mathrm{~h}$, the autogenous shrinkage of NM-modified cement based composites containing $3.0 \mathrm{wt}$. \% NM decreased by as much as $57.4 \%$; the autogenous shrinkage of CNTs-modified cement based composites containing $0.3 \mathrm{wt}$ \% CNTs decreased by as much as $19.4 \%$; the autogenous shrinkage of NC-modified cement based composites containing $2.0 \mathrm{wt}$ \% NC decreased by as much as $17.1 \%$. Electrochemical AC (Alternating Current) impedance spectroscopy results show that the resistance of the pore solution electrolyte of specimens containing nano-materials increases with age, and is less than that of specimens without nano-materials, which illustrates that the pore size of nano-modified cement based material is finer and autogenous shrinkage is smaller. Scanning electron microscope results show that the structure of cement matrix is denser with more hydration products by adding nano-materials. Nano-montmorillonite releases water to reduce self-drying effect during the process of hydration for its well water swelling. Carbon nanotubes have the nanometer filling effect and form a continuous network to restrain the early autogenous shrinkage of cement paste. Nano calcium carbonate not only decreases the porosity of the cement paste, but also reacts with tricalcium aluminate to generate the expanded product calcium carboaluminate for compensating autogenous shrinkage of cement paste.
\end{abstract}

Keywords: nano-materials; cement based materials; autogenous shrinkage properties; electrochemical impedance spectroscopy; microstructure

\section{Introduction}

Concrete cracking induced by shrinkage has always been considered as a major concern of concrete durability and structural safety control. In recent years, high strength concrete has been widely used in practical engineering [1]. Prior studies have shown that autogenous shrinkage is the primary factor leading to the cracking of high strength concrete. Autogenous shrinkage is defined as the unrestricted volumetric deformation of concrete without loss of mass and moisture under the condition of constant temperature and sealing [2-4]. Autogenous shrinkage is mainly attributed to chemical reaction and 
self-drying. The chemical shrinkage occurs when the total volume of hydration products is less than that of the reactants. After the structural skeleton of the cement paste is formed by hydration, the chemical shrinkage results in an air water interface in the matrix $[5,6]$. The internal relative humidity of the cement paste continues to decrease and the internal holes appear, resulting in the tensile stress and self-drying shrinkage [7-9].

Due to the nano-hydrated seed crystal effect, filling effect, etc., nanomaterials can be positive additives for cement based materials to improve the microstructure and restrict the autogenous shrinkage of cement based materials. Wang et al. [10] investigated the effect of nano- $\mathrm{SiO}_{2}$ on the shrinkage and early cracking sensitivity of lightweight aggregate concrete. They found that when the nano- $\mathrm{SiO}_{2}$ dosages increase from $1 \%$ to $3 \%$ by mass of the total binders, the total cracking area was decreased at early age. And, the interfacial transition zone (ITZ) between lightweight aggregate and paste was enhanced with 3\% nano- $\mathrm{SiO}_{2}$ addition. Polat et al. [11] reported that with the increases of nano-MgO content, the values of shrinkage of high performance cement materials decreased. Nano-MgO reduced the linear autogenous shrinkage by $53 \%, 56 \%$, and $80 \%$, respectively, when $2.5 \%$, $5.0 \%$, and $7.5 \%$ nano- $\mathrm{MgO}$, respectively, by weight of binder were used in mortar. Lim et al. [12] studied the influence of carbon nanofibers on the autogenous shrinkage and strength of ultra-high performance concrete. Results showed that homogeneously dispersed carbon nanofibers increased the compressive strength and compensated the autogenous shrinkage of ultra-high performance concrete, owing to that carbon nanofibers were capable of providing nano-bridges in the cement matrix. Norhasri [13] discussed on nano materials in concrete. Carbon nanotubes have the advantage of enhancing the flexibility and the strength of ultra-high performance concrete. Feneuil et al. [14] reported that the addition of nanomaterials accelerated the hydration processes especially in the early stages of hydration. And a reduction of the autogenous shrinkage by $50 \%$ for pastes containing small amounts $(0.01 \mathrm{wt} . \%)$ of nanomaterials. However, Kim et al. [15] found that CNT addition inhibited the hydration reaction at an early stage of curing, thereby reducing the autogenous shrinkage of the pastes and mortars.

In this work, three different nanomaterials of nano-montmorillonite (NM), Carbon nanotubes (CNTs), and nano calcium carbonate (NC) were used to study the influence on the autogenous shrinkage of cement based materials via the corrugated pipe method. The mechanisms of the effect of nanomaterials on the autogenous shrinkage of cement based materials were investigated by electrochemical impedance spectroscopy (EIS) and microstructural analysis.

\section{Materials and Methods}

\subsection{Raw Materials and Sample Fabrication}

Nanomaterials used in this experiment were nano-montmorillonite, carbon nanotubes (surface-modified multi-walled carbon nanotubes with carboxyl groups), and nano calcium carbonate. Physical properties of these three nanomaterials are shown in Tables 1-3. Other materials used in this experiment were alkylphenol polyoxyethylene ether (dispersing agent), tributyl phosphate (defoamer), cement (P.II 42.5R type), silica fume, and deionized water. The physical properties of cement and silica fume are shown in Tables 4 and 5 . Water to cement ratio is 0.3 . The cement based materials filled with varied nanomaterials were prepared. The NM additions were $1.0 \%, 2.0 \%$, and $3.0 \%$ by mass of cement and are denoted as CPNM1, CPNM2, and CPNM3, respectively. The CNTs additions were $0.1 \%, 0.2 \%$, and $0.3 \%$ by mass of cement and are denoted as CPCNTs01, CPCNTs02, and CPCNTs03, respectively. The NC additions were $1.0 \%, 2.0 \%$, and $3.0 \%$ by mass of cement and are denoted as CPNC1, CPNC2, and CPNC3, respectively. The reference group was labelled as $\mathrm{CP}$. 
Table 1. Properties of nano-montmorillonite [16].

\begin{tabular}{ccccc}
\hline Diameter/nm & Length/ $\mu \mathrm{m}$ & Purity/(wt.\%) & $\begin{array}{c}\text { Specific Surface } \\
\text { Area } /\left(\mathrm{m}^{2} / \mathrm{g}\right)\end{array}$ & Content(-COOH)/(wt.\%) \\
\hline$<8$ & $10 \sim 30$ & $>95$ & $>200$ & 5.58 \\
\hline
\end{tabular}

Table 2. Properties of carbon nanotubes [16].

\begin{tabular}{|c|c|c|c|c|}
\hline Diameter/nm & Aspect Ratio & Purity/(wt.\%) & $\begin{array}{c}\text { Specific Surface } \\
\text { Area } /\left(\mathrm{m}^{2} / \mathrm{g}\right)\end{array}$ & $\begin{array}{c}\text { Specific } \\
\text { Gravity } /\left(\mathrm{g} / \mathrm{cm}^{3}\right)\end{array}$ \\
\hline $20 \sim 45$ & $200 \sim 400$ & $>98.4$ & 750 & 2.6 \\
\hline
\end{tabular}

Table 3. Properties of nano calcium carbonate [16].

\begin{tabular}{cccc}
\hline Diameter/nm & Purity/(wt.\%) & $\begin{array}{c}\text { Specific surface } \\
\text { area } /\left(\mathbf{m}^{2} / \mathbf{g}\right)\end{array}$ & pH Value \\
\hline $15 \sim 40$ & 94.5 & $\geq 55$ & $9.0 \sim 10.5$ \\
\hline
\end{tabular}

Table 4. Properties of cement [16].

\begin{tabular}{|c|c|c|c|c|c|c|}
\hline \multirow{2}{*}{$\begin{array}{l}\text { Specific Surface } \\
\text { Area } /\left(\mathrm{m}^{2} / \mathrm{kg}\right)\end{array}$} & \multirow{2}{*}{$\begin{array}{l}\text { Initial Setting } \\
\text { Time/min }\end{array}$} & \multirow{2}{*}{$\begin{array}{l}\text { Final Setting } \\
\text { Time/min }\end{array}$} & \multicolumn{2}{|c|}{$\begin{array}{l}\text { Compressive } \\
\text { Strength/MPa }\end{array}$} & \multicolumn{2}{|c|}{ Flexural Strength/MPa } \\
\hline & & & 3 Day & 28 Day & 3 Day & 28 Day \\
\hline 338 & 152 & 207 & 33.1 & 57.2 & 6.8 & 9.3 \\
\hline
\end{tabular}

Table 5. Properties of silica fume [16].

\begin{tabular}{cccc}
\hline $\mathrm{SiO}_{2}$ Content/\% & Moisture Content/\% & $\begin{array}{c}\text { Average Particle } \\
\text { Size } / \mu \mathrm{m}\end{array}$ & $\begin{array}{c}\text { Specific Surface } \\
\text { Area/(m } / \mathbf{g})\end{array}$ \\
\hline$>96.0$ & $<3.0$ & $0.15 \sim 0.20$ & $>15,000$ \\
\hline
\end{tabular}

Nanomaterials (NM or CNTs or NC) were firstly added into a beaker dosed with dispersing agent (1:1 by weight with nanomaterials) and 1/2 dosage of water gross amount, and then stirred at the speed of $800 \mathrm{r} / \mathrm{min}$ with a magnetic stirring apparatus for approximately $15 \mathrm{~min}$, followed by ultrasonic treatment for $45 \mathrm{~min}$. Thereafter, cement, silica fume, defoamer, 0.5 remaining water, and the nanomaterials water admixture were added in a rotary mixer for $5 \mathrm{~min}$. Then, cement pastes with nano-material addition were cast.

\subsection{Testing}

The autogenous shrinkage of nano-modified cement pastes was measured by using the corrugated pipe method, which follows ASTM (American Society for Testing Materials) C 1698-09 [17]. Figure 1 shows a schematic illustration of the experimental setup used for the measurement. Firstly, one end of the tube was closed with an end plug, and then the paste was poured into the corrugated pipe. The tube was subsequently closed with the other plug after the pouring. Then, the corrugated pipe filled with cement paste was placed on an autogenous shrinkage testing device. The test set was kept in an ambient condition of $20^{\circ} \mathrm{C}$ and $50 \%$ relative humidity (RH). The duration of the test was $168 \mathrm{~h}$. The readings were recorded every $30 \mathrm{~min}$ for the first $12 \mathrm{~h}$, every $2 \mathrm{~h}$ from 12 to $72 \mathrm{~h}$, and every $6 \mathrm{~h}$ from $72 \mathrm{~h}$ to the end.

Samples with a size of $20 \mathrm{~mm} \times 20 \mathrm{~mm} \times 80 \mathrm{~mm}$ were fabricated and then vibrated for compaction. Four stainless steel mesh electrodes were embedded perpendicular to the length of the specimen and were symmetrical with respect to the midpoint along the length of the specimen. All samples were then covered and sealed with a plastic bag and demolded after $24 \mathrm{~h}$ curing in the standard curing chamber $\left(20^{\circ} \mathrm{C}, \mathrm{RH} 50 \%\right)$. Then, the samples were cured (consistent with the autogenous shrinkage 
curing condition) to a certain age, and the electrochemical impedance spectra of the samples were measured by the quadrupole method. In this paper, the EIS measurements were investigated using a Princeton PARSTAT 2273 electrochemical workstation with a frequency range of $1 \mathrm{~Hz}$ to $10^{5} \mathrm{~Hz}$, and the corresponding electrochemical parameters were analyzed using ZSimpWin software. At the same time, the specimens were used for scanning electron microscopy and X-ray diffraction tests.

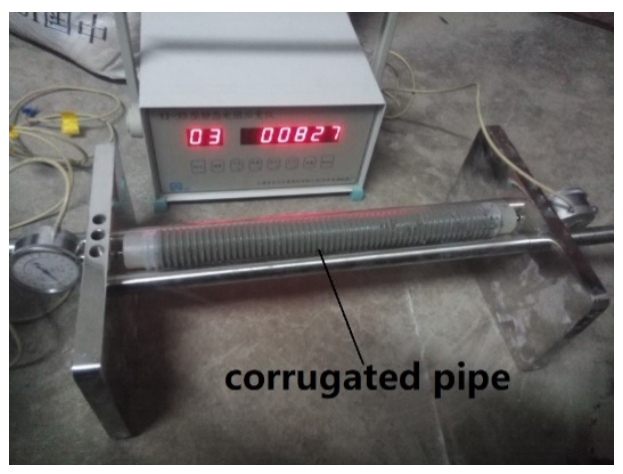

Figure 1. Experimental set-up for measuring autogenous shrinkage property.

Safety should be considered when dealing with nanomaterials [18]. During the sample preparation, protective measures were taken to avoid the body being touched by the nanoparticles. During the test of shrinkage, it was much better because the materials were sealed in the corrugated pipe.

\section{Results and Discussion}

\subsection{Autogenous Shrinkage Performance}

Figure 2 shows the changes of autogenous shrinkage strain of the nano-montmorillonite cement based materials and reference group samples with age. It can be seen from Figure 2 that the autogenous shrinkage of CP without nano-material can be divided into four different stages according to the development trend. During the rapid growth period (I), the cement paste changed from plastic state to solid state. Before the initial coagulation, the volume shrinkage caused by the cement hydration basically appeared to be decreased by the apparent volume due to the lack of sufficient frame strength to constrain volume deformation. After the initial coagulation, the rate of hydration reaction was accelerated. The self-drying effect led to the increase of capillary pressure, while the overall strength of the paste began to develop which has weak restraint on the apparent volume deformation. Thus the autogenous shrinkage of the cement pastes presented a fast growth trend. In the expansion period (II), the autogenous shrinkage appears to dropped temporarily from point A. As the hydration reaction continued, the moisture in the cement paste was continuously consumed. The self-drying effect was strengthened so that the autogenous shrinkage began to rise to the next stage slowly at point $\mathrm{B}$. The expansion at this stage may be ascribed to cement hydration which leads to an increase in the internal temperature causing the paste to expand [19]. In the slow growth period (III), the formation of the hardened cement paste skeleton has a certain inhibitory effect on the deformation of the apparent volume due to the gradual slowdown of the hydration reaction of the paste, resulting in a significant decrease of the autogenous shrinkage rate. In the relatively stable period (IV), the stiffness of the matrix was constantly enhanced due to the further weakened hydration reaction, which played a significant role in restraining the volume deformation. As a result, the volume stability was improved and the autogenous shrinkage showed a slight increase with age. Samples doped with nano-montmorillonite have the similar development law of autogenous shrinkage with that of reference group samples. 


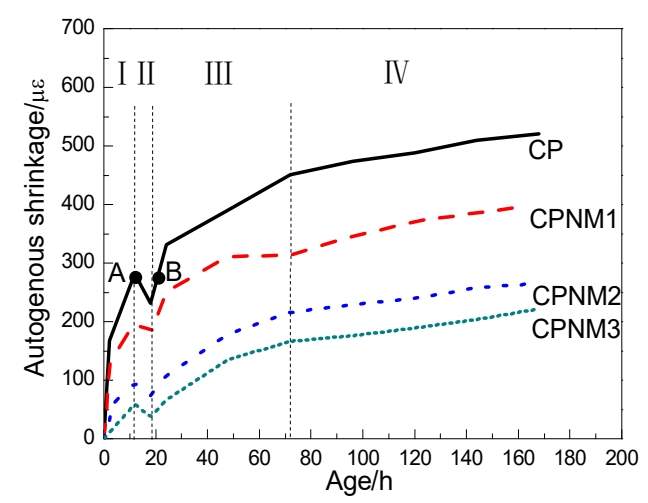

Figure 2. Autogenous shrinkage of nano-montmorillonite (NM)-modified cement based materials.

As can be seen from Figure 2, the autogenous shrinkage of each specimen mainly occurred in the first $72 \mathrm{~h}$. The autogenous shrinkage of CP, CPNM1, CPNM2 and CPNM3 at the age of $72 \mathrm{~h}$ accounts for $86.6 \%, 78.1 \%, 81.3 \%$ and $74.8 \%$ of the total autogenous shrinkage at the age of $168 \mathrm{~h}$, respectively. Compared with the $\mathrm{CP}$ group, the autogenous shrinkage of the specimen CPNM1, CPNM2 and CPNM3 is decreased by $23.0 \%, 48.9 \%$ and $57.4 \%$ respectively, at the age of $168 \mathrm{~h}$. The results demonstrate that the incorporation of NM into cement based materials has a significant improvement on the autogenous shrinkage of cement paste. The greater the amount of NM, the more obvious the improvement. This phenomenon attributes to the water swelling characteristic of NM itself. The interlayer water of cement paste can play the role of internal curing and relieve the self-drying effect. The self-expansion effect caused by the hydration reaction of conservation water compensated for partial shrinkage. Under the condition of the same chemical shrinkage, which caused by hydration of cement, the self-expansion effect can compensate for partial shrinkage of the volume which caused by chemical shrinkage in the early age of hydration due to the cement hydration of interlayer water, which results in a decrease of autogenous shrinkage [20,21].

The autogenous shrinkage strain of CNTs-modified cement based materials and the reference group specimens changed with age as shown in Figure 3. The tendency of autogenous shrinkage of each specimen is similar to that of NM-modified cement based materials. The autogenous shrinkage mainly happened in the first $72 \mathrm{~h}$ period. The autogenous shrinkage of CPCNTs01, CPCNTs02 and CPCNTs 03 at the age of $72 \mathrm{~h}$ accounts for $84.7 \%, 90.5 \%$, and $89.8 \%$ of the total autogenous shrinkage at the age of $168 \mathrm{~h}$, respectively. The decrease of shrinkage of CNTs-modified cement based materials in the expansion stage (II) caused by temperature rise is smaller than that of $\mathrm{CP}$, which may be related to the excellent thermal conductivity of CNTs. When CNTs are uniformly dispersed in the matrix, they can dissipate the heat generated by the cement hydration to the environment, which narrow the temperature difference between cement based materials and the environment. As a result, the expansion due to the temperature rise is reduced. The autogenous shrinkage of CPCNTs01, CPCNTs02 and CPCNTs 03 was reduced by $11.9 \%, 17.9 \%$, and $19.4 \%$, respectively, comparing with the reference group. This indicates that with the increase of the amount of CNTs, the decrease of autogenous shrinkage is increased, but the effect is not obvious. The uniform incorporation of CNTs in cement based materials can significantly reduce the number of pores in the matrix, especially the number of small pores, so as to reduce the capillary pressure $[22,23]$. On the other hand, the structure of the skeleton network formed by uniformly dispersed CNTs in the matrix can inhibit the autogenous shrinkage of the cement based materials [24,25]. 


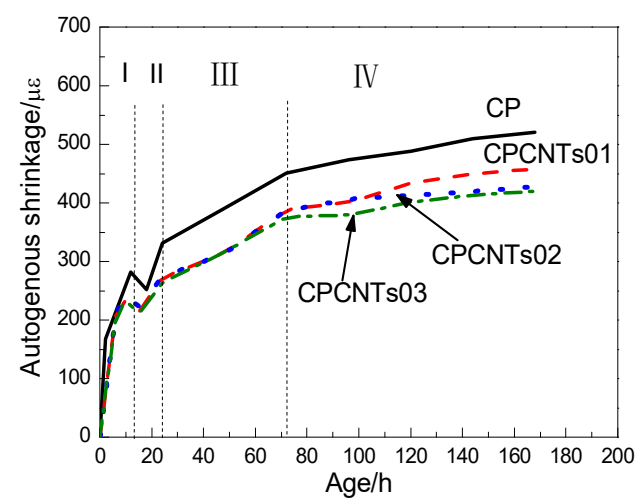

Figure 3. Autogenous shrinkage of CNTs-modified cement based materials.

The changes of the autogenous shrinkage strain of the nano- $\mathrm{CaCO}_{3}$ cement based materials and reference group samples over time were shown in Figure 4.After the incorporation of NC, with the development stages of autogenous shrinkage of cement based materials can also be divided into four stages. NC has little effect on autogenous shrinkage of cement based materials in the rapid growth stage (I). The autogenous shrinkage of CPNC1, CPNC2 and CPNC3 specimens is decreased by $8.6 \%$, $17.1 \%$ and $5.8 \%$ respectively, compared with $\mathrm{CP}$ group at the age of $168 \mathrm{~h}$. The results show that the incorporation of NC reduced the autogenous shrinkage of the paste. With the increase of the content of NC, the reduction of autogenous shrinkage increased firstly and then decreased, but the effect was not obvious. The effect of NC on cement based materials is due to the fact that NC could increase the content of calcium silicate hydrate (CSH) in cement paste and improve the alignment of calcium hydroxide $(\mathrm{CH})$, so that the interface structure gradually transitioned from plane to space to improve the interface performance. The non-directional arrangement of $\mathrm{CH}$ occupied more space, exhibiting a reduction of autogenous shrinkage [26]. On the other hand, the addition of NC produced a single-carbon type $\mathrm{C}_{3} \mathrm{~A} \cdot \mathrm{CaCO}_{3} \cdot 11 \mathrm{H}_{2} \mathrm{O}$, which has some expansibility to compensate for the autogenous shrinkage of cement based materials. When the content of $\mathrm{NC}$ increased to $3.0 \mathrm{wt} . \%$, the reduction of autogenous shrinkage decreased. The possible reason is that the specific surface area of NC is large. As the NC content increases, the probability of NC particles' agglomeration raises. It leads to nonuniform dispersion of NC in the matrix, increasing the air void content in cement paste, which weakens inhibitory effect of NC on the autogenous shrinkage of cement paste [27].

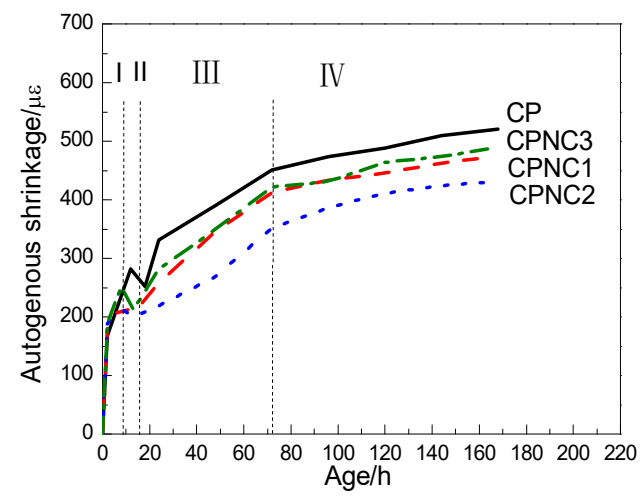

Figure 4. Autogenous shrinkage of NC-modified cement based materials.

Table 6 shows the final shrinkage strain values of cement based materials with different nanomaterials. In general, the value of the shrinkage strain for cement pastes containing nano-materials from small to large as follows: NM-modified cement based composites, CNTs-modified cement based composites, NC-modified cement based composites. This means the effect of nano-montmorillonite on autogenous shrinkage of cement paste is the most obvious, followed by carbon nanotubes then nano calcium carbonate. Nano-montmorillonite releases water to reduce the self-drying effect during 
the process of hydration for its well water swelling. The self-expansion effect caused by hydration reaction of conservation water compensated for partial shrinkage, which results in a decrease of autogenous shrinkage. Carbon nanotubes have the nanometer filling effect and form continuous network to restrain the early autogenous shrinkage of cement paste. Nano calcium carbonate not only decreases the porosity of the cement paste, but also reacts with tricalcium aluminate to generate the expanded product calcium carboaluminate for compensating autogenous shrinkage of cement paste. However, with the increase of the content of Nano calcium carbonate, the reduction of autogenous shrinkage decreased, which is owing to the nonuniform dispersion of Nano calcium carbonate at higher concentration in the matrix. Nano calcium carbonate at higher concentration appears poorly dispersed, forming agglomerates and bundles, which increases the air void content in cement paste and weakens inhibitory effect on the autogenous shrinkage of cement paste.

Table 6. Final shrinkage strain values of cement based materials with different nanomaterials.

\begin{tabular}{cc}
\hline Specimens & Final Shrinkage Strain/ $\mu \varepsilon$ \\
\hline CP & 520.1 \\
CPNM1 & 400.4 \\
CPNM2 & 265.4 \\
CPNM3 & 221.8 \\
CPCNTs01 & 458.3 \\
CPCNTs02 & 427.1 \\
CPCNTs03 & 419.0 \\
CPNC1 & 475.1 \\
CPNC2 & 431.0 \\
CPNC3 & 489.9 \\
\hline
\end{tabular}

\subsection{Electrochemical Impedance Spectroscopy}

The Nyquist diagrams of samples CP, CPNM2, CPCNTs03 and CPNC2 at different ages were shown in Figure 5. The value of the intersection point of the arc and the real axis in the Nyquist diagram reflect the value of pore solution resistance $R_{s}$. It can be seen from Figure 5 that the value of the solution resistance $\mathrm{R}_{\mathrm{S}}$ changes from small to large as follows: CPNM2, CPCNTs03, CPNC2 and CP. It can also be seen from Figure 5 that the intersection point of the circular arc and the real axis of Nyquist diagram of each sample moves from left to right as the age increases, which illustrates that $R_{S}$ is increasing $[28,29]$. And, the changes of the moving distance from $24 \mathrm{~h}$ to $72 \mathrm{~h}$ are larger than that from $72 \mathrm{~h}$ to $168 \mathrm{~h}$, which indicated that the internal structure of the paste changes more in the early age. This is consistent with the autogenous shrinkage changes in Section 3.1. The resistance of electrolyte in the pore solution represents the conductivity and porosity of the pore solution ions in the matrix. With the development of hydration process, the total amount of $\mathrm{Na}^{+}, \mathrm{K}^{+}$and $\mathrm{OH}^{-}$ions and other ions in the pore solution decreased and the resistance of pore solution electrolyte $R_{s}$ increased. The autogenous shrinkage of cement based materials due to self-drying results in an increase in the degree of unsaturation of the pore solution as the hydration progresses. The porosity and pore structure of the material changed, and the internal pore size was refined. The compactness of the cement paste was improved by hydration products and also by the filling effect of nanomaterials [30]. Therefore, the smaller the $R_{s}$ value of cement based material modified with nano-materials, the smaller the autogenous shrinkage is. 

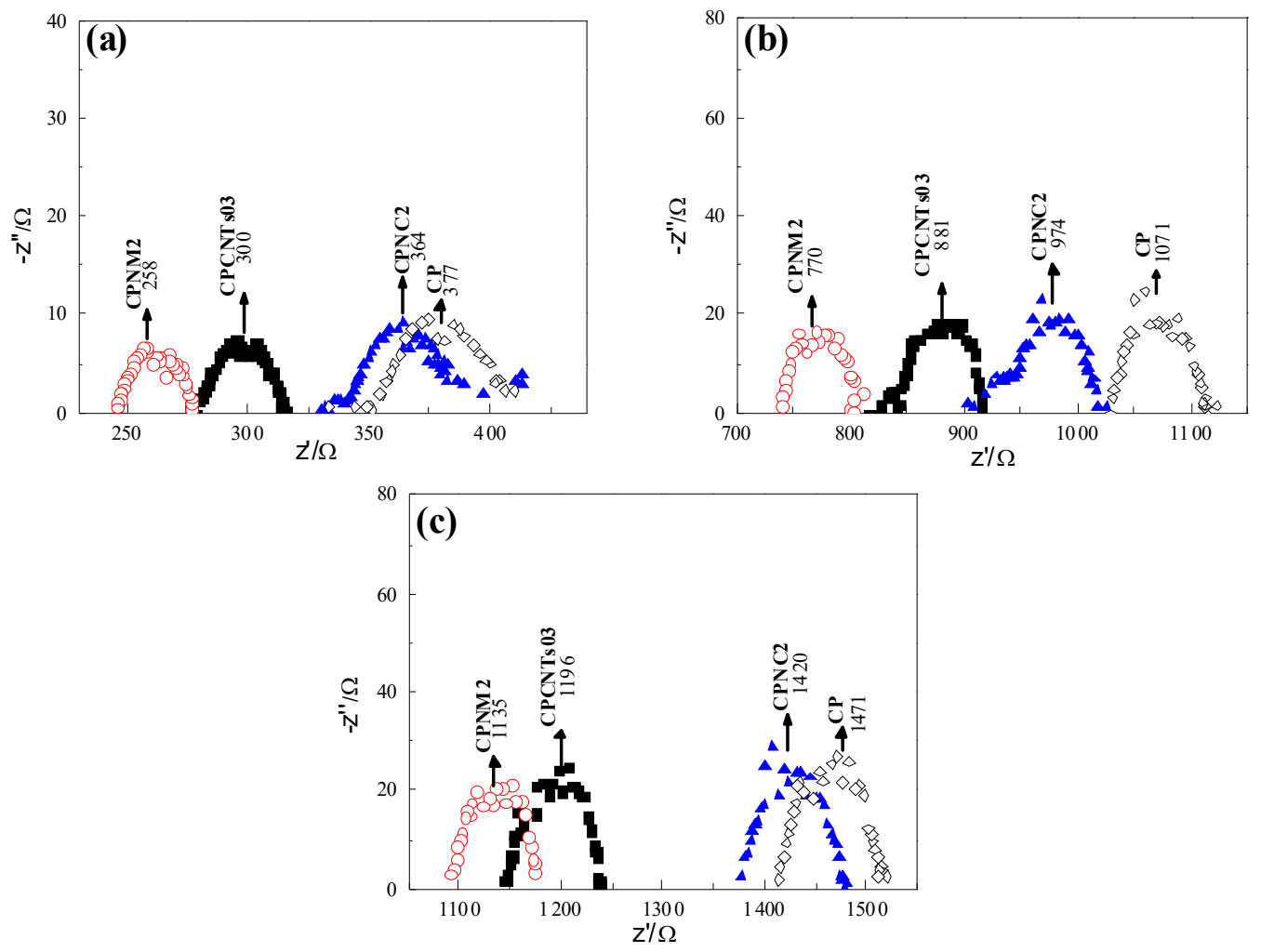

Figure 5. Nyquist diagram of nano-materials modified cement based materials at different ages: (a) $24 \mathrm{~h}$; (b) $72 \mathrm{~h}$; (c) $168 \mathrm{~h}$.

The equivalent circuit diagram shown in Figure 6 is used to fit the EIS data by using ZSimpWin software. $R_{S}$ represents electrolyte resistance of cement pastes pore solution, which is conversely proportional to the porosity and ion concentration. $R_{c t}$ represents charge transfer resistance and $Q$ represents constant phase element. The $R_{\mathrm{S}}$ values simulated by ZSimpWin are shown in Table 7 . It can be seen from the data that $R_{S}$ values of $C P$ group without adding nanometer materials were greater than other groups adding nanomaterials at all ages. The $\mathrm{R}_{\mathrm{S}}$ values of CPNM2 samples are less than that of CP samples due to the internal curing effect caused by water swelling of nano-montmorillonite, which compensated for the shrinkage of cement based materials to a certain extent. The $R_{s}$ value of CPCNTs03 sample decreases, which means that autogenous shrinkage of CPCNTs03 sample decreases accordingly. This could be owing to that the structure of the skeleton network formed by the uniformly mixed CNTs can restrain the autogenous shrinkage stress and the effect nano-packing of CNTs can reduce the shrinkage of the cement paste. The change of the $\mathrm{R}_{S}$ value of CPNC2 group is related to the shrinkage of cement based material due to its swelling product $\mathrm{C}_{3} \mathrm{~A} \cdot \mathrm{CaCO}_{3} \cdot 11 \mathrm{H}_{2} \mathrm{O}$ generated in the process of cement hydration. At the same age, $\mathrm{R}_{\mathrm{S}}$ values of $\mathrm{CPCNTs} 03$ group are greater than that of CPNM2 group, and less than that of CPNC2 group. The influence mechanisms of nanomaterials on the autogenous shrinkage of cement based materials and the $R_{S}$ value of each group are in accordance with the laws shown in Nyquist diagram, which further validates the accuracy of $R_{s}$ value variation law using Nyquist diagram of electrochemical impedance spectroscopy [31].

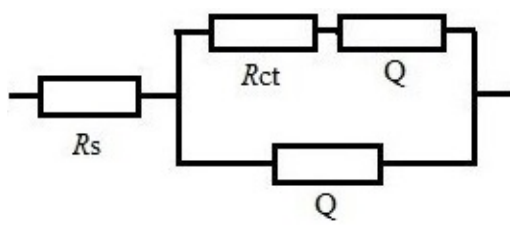

Figure 6. Equivalent circuit diagram of cement based materials. 
Table 7. Value of $R_{s}$ simulated by ZSimpWin.

\begin{tabular}{ccccc}
\hline \multirow{2}{*}{ Age $/ \mathbf{h}$} & $\mathbf{5}$ & $\mathbf{3} \mathbf{R}_{\mathbf{s}} / \mathbf{\Omega}$ \\
\cline { 2 - 5 } & $\mathbf{C P N M 2}$ & $\mathbf{C P C N T s 0 3}$ & CPNC2 \\
\hline 24 & 276.6 & 214.2 & 237.6 & 257.3 \\
72 & 831.4 & 668.2 & 716.4 & 782.7 \\
168 & 1113 & 840 & 959 & 1022 \\
\hline
\end{tabular}

\subsection{Microstructure Analysis}

Figure 7a displays the microstructure of the cement paste, and Figure $7 \mathrm{~b}-\mathrm{d}$ show the morphology of cement based materials with NM, CNTs, and NC, respectively. As shown in Figure 7a, the hydration products are mainly CSH gel, which are cross-linked into the paste. As can be seen from Figure $7 \mathrm{~b}$, the major hydration products with the addition of NM are CSH gel and Aft. They are relatively dispersed and the CSH is mostly in the form of flocculent gel. As presented in Figure 7c, with the addition of CNTs into the cement matrix, the carbon nanotubes wound and twisted together into a continuous network structure and tightly packed the hydration products [32]. Figure $7 \mathrm{~d}$ shows that CSH gel, calcium hydroxide crystals, and other hydration products form a relatively compact structure. Compared with the $\mathrm{CP}$ group, the addition of nanomaterials in cement based materials improved the microstructure and compaction of the matrix.

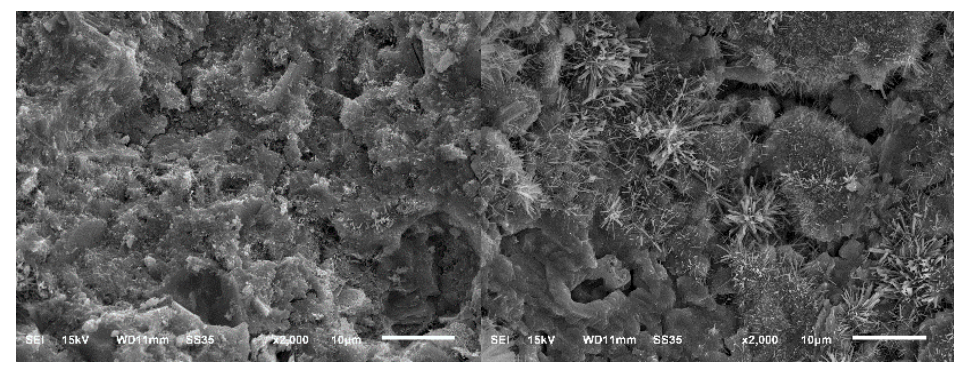

(a)

(b)

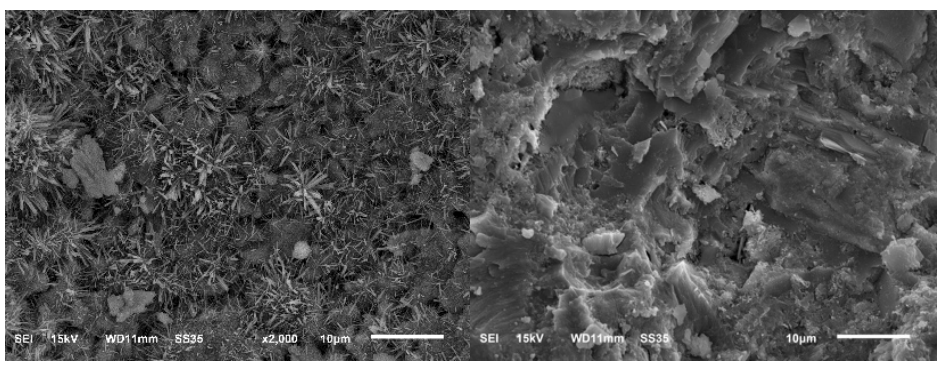

(c)

(d)

Figure 7. SEM images of cement pastes containing nano-materials: (a) CP; (b) CPNM2; (c) CPCNTs03; (d) CPNC2.

\section{Conclusions}

(1) The variation law of the autogenous shrinkage of cement based materials doped with nanomaterials with the increase of age is similar to that of reference samples. There are four main stages: (I) rapid growth period; (II) expansion period; (III) slow growth period; (IV) relatively stable period; and the autogenous shrinkage occurred mainly in the first $72 \mathrm{~h}$.

(2) Nanomaterials have a certain inhibitory effect on the autogenous shrinkage of cement paste. Compared with that of the reference group at the age of $168 \mathrm{~h}$, the autogenous shrinkage of NM-modified cement based composites with the content of $1.0 \mathrm{wt} . \%, 2.0 \mathrm{wt} . \%$, and $3.0 \mathrm{wt} . \% \mathrm{NM}$ 
decreased by $23.0 \%, 48.9 \%$, and $57.4 \%$, respectively; the autogenous shrinkage of CNTs-modified cement based composites with the content of $0.1 \mathrm{wt} . \%, 0.2 \mathrm{wt} . \%$, and $0.3 \mathrm{wt} . \%$ CNTs decreased by $11.9 \%, 17.9 \%$, and $19.4 \%$, respectively; the autogenous shrinkage of NC-modified cement based composites with the contents of $1.0 \mathrm{wt} . \%, 2.0 \mathrm{wt} . \%$, and $3.0 \mathrm{wt} . \%$ NC decreased by $8.6 \%, 17.1 \%$, $5.8 \%$, respectively.

(3) The Nyquist diagram and the fitting results of ZSimpWin show that the values of $R_{S}$ of the samples with nanomaterials are less than that of the reference sample at the same age, indicating that the nanomaterials restrain the autogenous shrinkage tendency of the cement based materials. And, the $R_{s}$ value of each sample increases with age. SEM test results further validate the conclusion of autogenous shrinkage and electrochemical tests that the cement based materials doped with NM or CNTs or NC have more compact microstructure and more abundant hydration products than the reference sample, and nanomaterials improve the early autogenous shrinkage performance of hydration paste.

In this work, nano-montmorillonite, carbon nanotubes and nano calcium carbonate were homogeneously dispersed and then mixed into cement paste. Autogenous shrinkage performance, electrochemical performance and microstructure were measured. Nyquist diagram of electrochemical impedance spectroscopy was used to validate the accuracy of $R_{S}$ value variation law. The findings in this work indicated that ideal methods contributed to reducing autogenous shrinkage performance of cement based materials by adding nanomaterials.

As CNTs and nano calcium carbonate appear poorly dispersed at a higher concentration, carbon nanotubes dosage $(0.1 \mathrm{wt} . \%, 0.2 \mathrm{wt} . \%, 0.3 \mathrm{wt} . \%)$ and nano calcium carbonate $(1.0 \mathrm{wt} . \%, 2.0 \mathrm{wt} . \%$, $3.0 \mathrm{wt} . \%)$ were used in cement paste in this work. Lower concentration of nano-materials restricted the inhibitory effect on the autogenous shrinkage to a certain extent. Future research work should consider to improve the dispersion of higher concentration of nano-materials in cement paste to enhance the inhibitory effect on the autogenous shrinkage.

Author Contributions: X.L. and J.Z. conceived and conducted the experiments; T.F. and J.Z. analyzed the data and wrote the paper.

Funding: This research was funded by National Key R\&D Program of China (No. 2017YFB0310100), Shanghai Construction Group Support Programs (No. 17JCYJ-07), State Key Laboratory of High Performance Civil Engineering Materials (No. 2016CEM011), and National Natural Science Foundation of China (No. 51508320, No. 51879093).

Conflicts of Interest: The authors declare no conflict of interest.

\section{References}

1. Wu, L.M.; Farzadnia, N.; Shi, C.J.; Zhang, Z.H.; Wang, H. Autogenous shrinkage of high performance concrete: A review. Constr. Build. Mater. 2017, 149, 62-65. [CrossRef]

2. Demir, L.; Sevim, O.; Tekin, E. The effects of shrinkage-reducing admixtures used in self-compacting concrete on its strength and durability. Constr. Build. Mater. 2018, 172, 153-165. [CrossRef]

3. Yoo, D.Y.; Kim, S.; Kim, M.J. Comparative shrinkage behavior of ultra-high-performance fiber-reinforced concrete under ambient and heat curing conditions. Constr. Build. Mater. 2018, 162, 406-419. [CrossRef]

4. Shen, D.J.; Jiang, J.L.; Shen, J.X.; Yao, P.P.; Jiang, G.Q. Influence of curing temperature on autogenous shrinkage and cracking resistance of high-performance concrete at an early age. Constr. Build. Mater. 2016, 103, 67-76. [CrossRef]

5. Yousefieh, N.; Joshaghani, A.; Hajibandeh, E.; Shekarchid, M. Influence of fibers on drying shrinkage in restrained concrete. Constr. Build. Mater. 2017, 148, 833-845. [CrossRef]

6. Plank, J.; Sakai, E.; Miao, C.W.; Yu, C.; Hong, J.X. Chemical admixtures-Chemistry, applications and their impact on concrete microstructure and durability. Cem. Concr. Res. 2015, 78, 81-99. [CrossRef]

7. Ghafari, E.; Ghahari, S.; Costa, H.; Júlio, E.; Portugal, A.; Durães, L. Effect of supplementary cementitious materials on autogenous shrinkage of ultra-high performance concrete. Constr. Build. Mater. 2016, 127, 43-48. [CrossRef] 
8. Oliveira, M.J.; Ribeiro, A.B.; Branco, F.G. Shrinkage of self-compacting concrete. A comparative analysis. J. Build. Eng. 2017, 9, 117-124. [CrossRef]

9. Liu, J.H.; Shi, C.J.; Ma, X.W.; Khayat, K.H.; Zhang, J.; Wang, D.H. An overview on the effect of internal curing on shrinkage of high performance cement-based materials. Constr. Build. Mater. 2017, 146, 702-712. [CrossRef]

10. Wang, X.F.; Huang, G.Y.; Wu, G.Y.; Fang, C.; Li, D.W.; Han, N.X.; Xing, F. Effect of nano-SiO 2 on strength, shrinkage and cracking sensitivity of lightweight aggregate concrete. Constr. Build. Mater. 2018, 175, 115-125. [CrossRef]

11. Polat, R.; Demirboga, R.; Karagol, F. The effect of nano-MgO on the setting time, autogenous shrinkage, microstructure and mechanical properties of high performance cement paste and mortar. Constr. Build. Mater. 2017, 156, 208-218. [CrossRef]

12. Lim, J.; Raman, S.N.; Safiuddin, M.; Zain, M.; Hamid, R. Autogenous shrinkage, microstructure, and strength of ultra-high performance concrete incorporating carbon nanofibers. Materials 2019, 12, 320. [CrossRef] [PubMed]

13. Norhasri, M.S.; Hamidah, M.S.; Fadzil, A.M. Applications of using nano material in concrete: A review. Constr. Build. Mater. 2017, 133,91-97. [CrossRef]

14. Feneuil, B.; Habermehi-Cwirzen, K.; Cwirzen, A. Contribution of CNTs/CNFs morphology to reduction of autogenous shrinkage of Portland cement paste. Front. Struct. Civ. Eng. 2017, 11, 255. [CrossRef]

15. Kim, G.M.; Yoon, H.N.; Lee, H.K. Autogenous shrinkage and electrical characteristics of cement pastes and mortars with carbon nanotube and carbon fiber. Constr. Build. Mater. 2018, 177, 428-435. [CrossRef]

16. Zuo, J.Q.; Yao, W.; Wu, K.R. Seebeck effect and mechanical properties of carbon nanotube-carbon fiber/cement nanocomposites. Fuller. Nanotub. Carbon Nanostruct. 2015, 23, 383-391. [CrossRef]

17. ASTM. C 1698-09 Standard Test Method for Autogenous Strain of Cement Paste and Mortar; ASTM International: West Conshohocken, PA, USA, 2014; pp. 1-8.

18. Silva, F.; Arezes, P.; Swuste, P. Risk management: Controlling occupational exposure to nanoparticles in construction. In Nanotechnology in Eco-Efficient Construction, 2nd ed.; Pacheco-Torgal, F., Diamanti, M.V., Nazari, A., Granqvist, C.G., Pruna, S., Amirkhanian, S., Eds.; Woodhead Publishing: Duxford, UK, 2019; pp. 755-784.

19. Shen, P.L.; Lu, L.N.; He, Y.J.; Rao, M.J.; Fu, Z.D.; Wang, F.Z.; Hu, S.G. Experimental investigation on the autogenous shrinkage of steam cured ultra-high performance concrete. Constr. Build. Mater. 2018, 162, 512-522. [CrossRef]

20. Yang, J.; Wang, F.Z. Influence of assumed absorption capacity of superabsorbent polymers on the microstructure and performance of cement mortars. Constr. Build. Mater. 2019, 204, 468-478. [CrossRef]

21. Rashad, A.M. A comprehensive overview about the effect of nano-SiO $\mathrm{O}_{2}$ on some properties of traditional cementitious materials and alkali-activated fly ash. Constr. Build. Mater. 2014, 52, 437-464. [CrossRef]

22. Liew, K.M.; Kai, M.F.; Zhang, L.W. Carbon nanotube reinforced cementitious composites: An overview. Compos. Part A Appl. Sci. Manuf. 2016, 91, 301-323. [CrossRef]

23. Wong, E.; Sheehan, P.; Lieber, C. Nanobeam mechanics: elasticity, strength and toughness of nanorods and nanotubes. Science 1997, 277, 1971-1975. [CrossRef]

24. Rao, A.M.; Eklund, P.C.; Bandow, S.; Thess, A.; Smalley, R.E. Evidence for charge transfer in doped carbon nanotube bundles from Raman scattering. Nature 1997, 388, 257-259. [CrossRef]

25. Zuo, J.; Yao, W.; Liu, X.Y.; Qin, J.J. Sensing properties of carbon nanotube-carbon fiber/cement nanocomposites. J. Test. Eval. 2012, 40, 838-843. [CrossRef]

26. Qian, X.; Wang, J.L.; Wang, L.; Fang, Y. Enhancing the performance of metakaolin blended cement mortar through in-situ production of nano to sub-micro calcium carbonate particles. Constr. Build. Mater. 2019, 196, 681-691. [CrossRef]

27. Nejad, F.M.; Tolouei, M.; Nazari, H.; Naderan, A. Effects of calcium carbonate nanoparticles and fly ash on mechanical and permeability properties of concrete. Adv. Civ. Eng. Mater 2018, 7, 651-668. [CrossRef]

28. Wu, Z.M.; Shi, C.J.; Khayat, K.H.; Wan, S. Effects of different nanomaterials on hardening and performance of ultra-high strength concrete (UHSC). Cem. Concr. Compos. 2016, 70, 24-34. [CrossRef]

29. Monticelli, C.; Frignani, A.; Trabanelli, G. A study on corrosion inhibitors for concrete application. Cem. Concr. Res. 2000, 30, 635-642. [CrossRef] 
30. Pruckner, F.; Theiner, J.; Eri, J.; Nauer, G.E. In-situ monitoring of the efficiency of the cathodic protection of reinforced concrete by electrochemical impedance spectroscopy. Electrochim. Acta 1996, 41, 1233-1238. [CrossRef]

31. Andrade, C.; Keddam, M.; Novoa, X.R.; Perez, M.C.; Rangel, C.M.; Takenouti, H. Electrochemical behaviour of steel rebars in concrete: Influence of environmental factors and cement chemistry. Electrochim. Acta 2001, 46, 3905-3912. [CrossRef]

32. Zuo, J.Q.; Yao, W.; Xu, J.; Chen, Y.Q.; Liu, X.Y. Effects of carbon nanotube-carbon fiber cementitious conductive anode for cathodic protection of reinforced concrete. J. Test. Eval. 2017, 45, 1777-1786. [CrossRef]

(C) 2019 by the authors. Licensee MDPI, Basel, Switzerland. This article is an open access article distributed under the terms and conditions of the Creative Commons Attribution (CC BY) license (http://creativecommons.org/licenses/by/4.0/). 